\title{
Factors Associated with Head Start Staff Participation in Classroom-Based Professional Development
}

\author{
Carol M. Trivette ${ }^{1}$, Melinda Raab ${ }^{1}, \&$ Carl J. Dunst ${ }^{1}$ \\ ${ }^{1}$ Orelena Hawks Puckett Institute, Morganton, North Carolina, USA \\ Correspondence: Carol M. Trivette, Orelena Hawks Puckett Institute, 128 S. Sterling St., Morganton, North Carolina \\ 28655, USA. E-mail: ctrivette@ puckett.org
}

Received: June 26, 2014 Accepted: July 21, 2014 Online Published: August 19, 2014

doi:10.11114/jets.v2i4.449 URL: http://dx.doi.org/10.11114/jets.v2i4.449

\begin{abstract}
Factors associated with Head Start staff participation in a classroom-based professional development project to promote their use of evidence-based child learning opportunity practices and evidence-based responsive teaching procedures were examined in a study of 36 teachers and teacher assistants in 19 different classrooms. The factors constituting the focus of investigation included work climate, staff belief appraisals (career aspirations, personal motivation, Developmentally Appropriate Practices beliefs), staff receptiveness to the professional development training, staff judgments of the social validity of the practices constituting the focus of training, and staff background characteristics (age, education, years of experience). Results showed that Head Start staff members' personal beliefs, receptiveness to the training, and their judgments of the social validity of the classroom practices constituting the focus of training were related to staff judgments of their participation in the training which in turn were related to their active engagement in learning to use the classroom practices. The implications of the findings for practice are described in terms of the need to use methods and procedures that actively engage staff in professional development opportunities.
\end{abstract}

Keywords: professional development, work climate, belief appraisals, social validity, receptiveness to training

\section{Introduction}

A hallmark of high quality early childhood intervention programs is ongoing professional development (Neuman \& Kamil, 2010; Snell, Forston, Stanton-Chapman, \& Walker, 2012; Tout, Zaslow, \& Berry, 2006). Both research and experience, however, indicate that early childhood professionals' participation in training, including Head Start staff, more often than not is quite varied (e.g., Domitrovich, Gest, Sukhdeep, Jones, \& DeRousie, 2009; Downer, Locasale-Crouch, Hamre, \& Pianta, 2009; Ellis, 1998; Livneh \& Livneh, 1999; Torquati, Raikes, \& Huddleston-Casas, 2007; Trivette \& Raab, 2011). The purposes of the analyses described in this paper were to (a) identify factors associated with Head Start staff's active participation in training to promote their adoption and use of two different types of evidence-based classroom practices and (b) determine which variables, if any, covaried with the predictors of active staff participation in and the perceived benefits of the training. The goal was to identify the nature of the relationships among a number of staff personal belief appraisals and training-related predictor measures and to identify the conditions under which staff participated in and benefited from the training afforded Head Start teachers and teacher assistants.

The particular variables that were the focus of investigation are ones that have been found or implicated to be determinants of receptiveness to and participation in training or other professional development learning opportunities for improving early childhood professional knowledge and skills in using evidence-based or recommended classroom practices (Bozack, 2008; Downer et al., 2009; Ellis, 1998; Sugawara, Ruder, \& Burt, 1998). Wagner and French (2010), for example, examined the relationships among early childhood teacher work climate, personal motivation, and participation in professional development, and found that the social ecology of preschool programs together with a personal sense of responsibility for professional growth were correlated with engagement in professional development activities. Similarly, Dunst, Watson, Roper, and Batman (2011) found that the social ecology of an early childhood intervention program was related to staff members' judgments of their personal responsibility for seeking out and participating in professional development activities. Bozack (2008), in a review of factors associated with early childhood practitioners' participation in professional development activities, concluded that there are many "reasons 
why teachers vary in their responsiveness to professional development initiatives" (p. 28).

\subsection{Factors Associated with Participation in Professional Development}

Wagner and French's (2010) model of factors influencing early childhood practitioners' participation in professional development activities postulates the following three sets of variables as important determinants or covariates of teacher change: work environment, belief appraisals in terms of personal responsibility (motivation) for change, and teacher background characteristics. In addition to examining these factors, we also assessed Head Start staff receptiveness to training and their social validity judgments of the importance and acceptability (Foster \& Mash, 1999) of the classroom practices constituting the focus of training. Receptiveness was examined because our research on classroom practices indicates that staff who are more responsive to on-site, classroom-based practices training are more likely to demonstrate more improvements in the use of the practices constituting the focus of that training (Dunst \& Raab, 2010). Our research also has shown that the likelihood that practitioners "buy into" the use of new or innovative practices is dependent on their judgments of the benefits of the practices constituting the focus of intervention (e.g., Dunst, Pace, \& Hamby, 2007; Trivette, Dunst, Hamby, \& Pace, 2007).

The professional development measures constituting the focus of investigation included number of attended training sessions, hours of staff participation in the training, staff engagement in the training, and staff judgments of their experiences with the evidence-based professional development practice used to provide the training (Dunst \& Trivette, 2009; Trivette, Raab, \& Dunst, 2012b). The latter measure was of special interest because two or more staff could receive the same amount or dose of training but the benefits from their training-related experiences might be quite different (Neuman \& Wright, 2010; Ramey et al., 2011). Bozack (2008), for example, found that elementary teachers' beliefs about the importance of ongoing professional development were related to how often they sought out and met with mentors. Similarly, Bruder et al. (2013) found that early childhood practitioners' beliefs about how well they were prepared to work with young children and their families were related to their use of recommended early childhood practices. The extent to which Head Start staff beliefs about training were related to active engagement in training was another focus of the analyses described in this paper. The findings were expected to shed light on the conditions under which staff were likely to be receptive to and actively engaged in the professional development training.

\subsection{Study Hypotheses}

Based on previous research, we hypothesized that staff judgments of their work climates would be related to their personal belief appraisals (career aspirations, personal motivation, beliefs about child learning); personal beliefs would be related to judgments of the value of the classroom practices constituting the focus of training; and their receptiveness to the training would be related to their participation in the training (Ellis, 1998; Sugawara et al., 1998; Wagner \& French, 2010). We also hypothesized that positive judgments about the ways in which staff were involved in training would be related to staff active engagement in the training and use of the classroom practices constituting the focus of training. We expected, based on previous research, that staff with more years of formal education would report more positive benefits from the training (Domitrovich et al., 2009; Livneh \& Livneh, 1999). The need for the types of analyses described in this paper is based on the fact that "early childhood teachers' motivation for professional development remains virtually unexplored" (Wagner \& French, 2010, p. 154).

\section{Method}

\subsection{Participants}

The participants were 36 early childhood staff (19 teachers and 17 teacher assistants) in 19 classrooms in two Head Start preschool classroom programs in the southeastern United States. Table 1 shows the background characteristics of the staff. Most of the participants were African-American, 31 years of age or older, had associate's or bachelor's degrees, and had, on average, between 6 and 15 years of experience. One-third of the participants had Child Development Associate credentials, but only one teacher had a state teaching certification.

The average number of children in each classroom was 19 ( $\mathrm{SD}=1$, range $=17$ to 20$)$. The majority of classrooms included mixed age groups of 3- to 5-year-old children. Fourteen of the classrooms included 3 year olds; 17 classrooms included 4 year olds; and two classrooms included 5 year olds. The children's ethnicities were African American (45\%), Caucasian (26\%), Latino or Hispanic (21\%), Asian American (2\%), or other or biracial (6\%). All but three of the classrooms included children with special needs. Sixteen of the classrooms $(84 \%)$ included one or more children for whom English was not their first language. 
Table 1. Background Characteristics of the Study Participants

\begin{tabular}{|c|c|c|}
\hline Participant Characteristics & Number & Percent \\
\hline \multicolumn{3}{|l|}{ Ethnicity } \\
\hline African American & 26 & 72 \\
\hline Caucasian & 10 & 28 \\
\hline \multicolumn{3}{|l|}{ Age (Years) } \\
\hline 23-30 & 6 & 17 \\
\hline $31-40$ & 15 & 42 \\
\hline $41-50$ & 6 & 17 \\
\hline $51-63$ & 9 & 25 \\
\hline \multicolumn{3}{|l|}{ Education } \\
\hline High School & 4 & 11 \\
\hline Some College & 11 & 31 \\
\hline Associates Degree & 15 & 42 \\
\hline Bachelors Degree & 6 & 17 \\
\hline \multicolumn{3}{|l|}{ Experience (Years) } \\
\hline $1-5$ & 8 & 22 \\
\hline $6-10$ & 12 & 33 \\
\hline $11-15$ & 6 & 17 \\
\hline $16-20$ & 7 & 19 \\
\hline $21-25$ & 3 & 8 \\
\hline \multicolumn{3}{|c|}{ Child Development Associate } \\
\hline Yes & 13 & 36 \\
\hline No & 23 & 64 \\
\hline \multicolumn{3}{|l|}{ State Teacher Certification } \\
\hline Yes & 1 & 3 \\
\hline No & 35 & 97 \\
\hline
\end{tabular}

\subsection{Procedure}

\subsubsection{Classroom Practices}

The participants were taught to use evidence-based child learning opportunities (Dunst, Bruder, Trivette, Raab, \& McLean, 2001; Dunst \& Raab, 2012) and evidence-based naturalistic responsive teaching procedures (Dunst, Raab, \& Trivette, 2011; Raab \& Dunst, 2009) with the children in their classrooms. The evidence-based child learning opportunity practices were ones that actively involved children in a broad range of interest-based learning activities building on existing child strengths and promoting the development of new competencies. The teacher-instructional practices were ones that supported and encouraged child competence through responsiveness to the children's existing or emerging capabilities. Table 2 includes examples of the two types of classroom practices.

The child learning opportunity practices are based on research demonstrating the importance of (a) using children's interests as the basis for identifying child learning activities, (b) providing children different kinds of interest-based learning activities, and (c) increasing the number of child learning opportunities within and across classroom activities (Dunst et al., 2001; Raab \& Dunst, 2007). The responsive teaching instructional practices are based on research demonstrating the importance of (a) promoting child engagement in interest-based activities, (b) responding to and supporting child behavior in the activities, and (c) encouraging child behavior elaboration during interest-based learning (Raab \& Dunst, 2009). 
Table 2. Examples of the Training Content for the Two Types of Classroom Practices

\begin{tabular}{|c|c|}
\hline Training Content Areas & Examples \\
\hline \multicolumn{2}{|l|}{ Child Learning Opportunities } \\
\hline \multirow[t]{2}{*}{ Identifying child interests } & Recognize that all children have personal interests \\
\hline & Observe a child to identify his or her interests \\
\hline \multirow{2}{*}{$\begin{array}{l}\text { Selecting and providing interest-based } \\
\text { child learning activities }\end{array}$} & Create interest-based learning activities \\
\hline & $\begin{array}{l}\text { Use activities that encourage broad-based child behavior } \\
\text { expression }\end{array}$ \\
\hline \multirow[t]{2}{*}{$\begin{array}{l}\text { Increasing interest-based child learning } \\
\text { opportunities }\end{array}$} & $\begin{array}{l}\text { Create opportunities for a child to participate frequently in } \\
\text { interest-based activities }\end{array}$ \\
\hline & Engage the child a wide variety of interest-based activities \\
\hline \multicolumn{2}{|l|}{ Teacher Instructional Practices } \\
\hline \multirow[t]{2}{*}{$\begin{array}{l}\text { Child engagement in interest-based } \\
\text { activities }\end{array}$} & $\begin{array}{l}\text { Use a child's interests to engage the child in interest-based } \\
\text { learning activities }\end{array}$ \\
\hline & Follow a child's lead \\
\hline \multirow[t]{2}{*}{ Responsiveness to child behavior } & $\begin{array}{l}\text { Respond promptly and positively to child engagement in } \\
\text { activities }\end{array}$ \\
\hline & Match teacher responses to a child's behavior \\
\hline \multirow[t]{2}{*}{ Encourage child behavior elaboration } & Respond to a child with open-ended questions \\
\hline & Encourage a child to produce or try new behavior \\
\hline
\end{tabular}

\subsubsection{Professional Development}

Staff were taught to use the classroom practices by the same coach in all of the Head Start classrooms using an evidence-based adult learning procedure called the Participatory Adult Learning Strategy (PALS; Dunst \& Trivette, 2009; Trivette, Raab, \& Dunst, 2012a). The coach was scheduled to meet with each teacher and teacher assistant once a week for 4 months. On average, the coach spent 60 minutes with a teacher and teacher assistant during each on-site visit. The average number of sessions attended by each teacher and teacher assistant was $13.44(\mathrm{SD}=2.22)$, and the average number of hours of training each staff received was 35.40 (SD = 7.04). In a large majority of coaching sessions $(94 \%)$, the coach worked with both the teacher and teacher assistant at the same time where both participants were involved in the training in the same manner.

PALS included methods for introducing and demonstrating the use of the targeted practices, Head Start staff application and evaluation of the use of the practices, coach-facilitated Head Start staff reflection on and self-assessment of their mastery of the practices, and coach-facilitated Head Start staff identification of and participation in additional learning opportunities to reinforce competence acquisition. Figure 1 shows the manner in which the training was conducted and the coach actively engaged the participants in learning to use the classroom practices.

The coach first introduced a practice to the staff by both describing the key characteristics of a practice (e.g., identifying child interests) and providing examples of how the practice could be implemented (e.g., observational assessments). The coach used the children's interactions with materials and peers in the classroom to illustrate the key characteristics of a practice (e.g., interest-based child engagement in play) and to describe the differences between practices that were consistent or inconsistent with a targeted practice (e.g., interest-based vs. non-interest-based child learning). The process of introducing a practice and illustrating or demonstrating the use of the practice was repeated for each of the targeted practices in subsequent training sessions. 


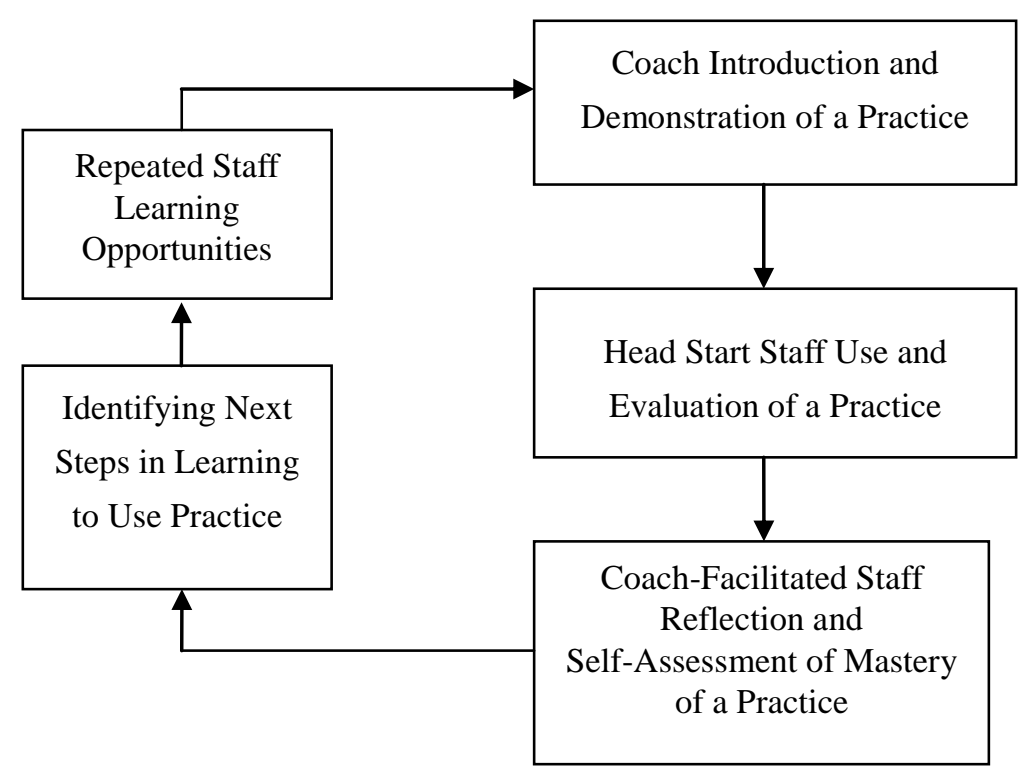

Figure 1. Key components of the PALS professional development practice.

Teacher and teacher assistant application of a practice involved both classroom staff use of a practice (e.g., responsiveness to child initiations) and coach-guided staff evaluation of the practice (e.g., child behavioral consequence of teacher responsiveness). The teachers and teacher assistants were engaged in multiple opportunities to use a practice (e.g., use of responsive teaching with three or four children) where observations of the use of the practice by the coach were the foundations for providing feedback, guidance, and coach-facilitated teacher evaluation of her use of the practice (e.g., having a teacher and assistant identify what did and did not work and why).

Facilitating mastery (deep understanding) of a practice occurred by using performance standards to have the teachers and assistants reflect on their understanding and use of a practice and by joint discussions and identification of additional learning opportunities that would provide the staff new opportunities to improve their use of a practice. An important feature of the training was the use of performance checklists to engage the staff in self-assessment of their understanding and mastery (Dunst, Trivette, \& Raab, 2014). There were two performance checklists, one for the child learning opportunities classroom practices, and one for teacher instructional practices.

\subsection{Predictor Measures}

The variables constituting the focus of investigation included Head Start staff background characteristics (age, years of formal education, years of early childhood experience, staff position), Head Start program work climate, participant personal belief appraisals (career aspirations, personal motivation, DAP beliefs), and two training-related measures (receptiveness to the PALS training, and staff judgments of the social validity of the evidence-based classroom practices). Table 3 lists the study measures and the means, standard deviations, and range of scores on each of the predictors. The background, work climate, and personal belief measures were all obtained prior to the initiation of the training. The staff receptiveness and social validity measures were obtained throughout the course of the training.

Table 3. Means, Standard Deviations and Range of Scores for the Predictor Variables and Dependent Measures

\begin{tabular}{|c|c|c|c|}
\hline Study Measures & Mean & Standard Deviation & Range \\
\hline \multicolumn{4}{|l|}{ Background Characteristics } \\
\hline Age (Years) & 41.61 & 10.73 & $23-63$ \\
\hline Education & 5.53 & 1.13 & $3-7$ \\
\hline Years of Experience & 11.32 & 6.29 & $1-22$ \\
\hline Staff Position ${ }^{\mathrm{a}}$ & 0.53 & 0.51 & $0-1$ \\
\hline \multicolumn{4}{|l|}{ Head Start Program } \\
\hline Work Climate & 51.25 & 9.90 & $29-66$ \\
\hline
\end{tabular}

Personal Beliefs 
Career Aspirations

Personal Motivation

DAP Beliefs

Training-Related Variables

Receptiveness to Training

Social Validity Judgments

Outcome Measures

Number of Sessions

Total Training Time (hours)

Staff Engagement

PALS Ratings
29.75

27.14

61.22

7.43

52.22

13.44

35.37

38.56

92.58
3.55

2.79

5.40

1.61

8.14

$2.8-10$

26-60

9-18

24-50

20-62

59-100

${ }^{\mathrm{a}}$ Teacher $=1$, Teacher Assistant $=0$.

\subsubsection{Background Variables}

Head Start staff age and years of early childhood experience were coded in years as continuous variables. Formal education was coded as an ordinal variable: Less than high school, high school (including a General Education Diploma), some college, associate's degree (including a vocational/technical diploma), bachelor's degree, or master's degree. Staff position was coded as teacher (1) or teacher assistant (0).

\subsubsection{Work Climate}

Teachers and teacher assistants completed a 14-item rating scale adapted from the Home Visitor Interview (Partners for a Healthy Baby, 2006), measuring their judgments of their workplace climate. The items assessed administrative leadership in the Head Start program (e.g., The program director communicates a clear vision of what the program should accomplish), administrative support for the staff (e.g., The program director recognizes when I do a good job), teacher participation in program-related decision-making (e.g., Program staff have the opportunity to influence decisions about their work), and the work atmosphere of the program (e.g., The Head Start program is a pleasant place to work). The items were rated on a 5-point scale ranging from 1 (strongly disagree) to 5 (strongly agree). The internal reliability of the scale was determined using Carmines' theta, a special case of Cronbach's alpha (Carmines \& Zeller, 1979). Theta for the 14 items was .88. A summated score of the ratings on the 14 items was used as the work climate measure.

\subsubsection{Career Aspirations}

Teachers and teacher assistants completed a 7-item scale adapted from the Home Visitor Interview (Partners for a Healthy Baby, 2006), measuring their career orientations. The items asked teachers to indicate how they viewed their positions in the Head Start programs (e.g., I see my current position as work I feel committed to; I see my current position as a personal calling). The items were rated on a 5-point scale ranging from 1 (not at all the way I feel) to 5 (exactly the way I feel). Theta for the seven items was .75. The sum of the ratings was used as the measure of career aspirations.

\subsubsection{Personal Motivation}

Teachers' and teacher assistants' motivation for pursuing training and learning opportunities was assessed using an investigator-developed scale that included six items assessing personal motivation for learning (e.g., I pursue training opportunities because I want to improve my skills as a teacher; I pursue training opportunities because it is beneficial to learn more about early education). Teachers rated the items on a 5-point scale ranging from 1 (not at all true) to 5 (very true). Theta for the six items was .76. Ratings on these six items were summed to provide a measure of teachers' personal motivation for training.

\subsubsection{Developmentally Appropriate Practices (DAP) Beliefs}

Teachers' and teacher assistants' beliefs about Developmentally Appropriate Practices (Bredekamp \& Copple, 1997) were assessed using a subset of items from the beliefs section of the Teacher Beliefs and Practices Survey (Burts, Buchanan, Charlesworth, \& Jambunathan, 2000). This survey, developed especially for preschool teachers, is an adaptation of the Teacher Questionnaire (Charlesworth, Hart, Burts, \& Hernandez, 1991) that has been used to assess the early childhood beliefs of teachers of children kindergarten age and older (e.g., Vartuli, 1999). In a study of the 
psychometric properties of the Burts et al. (2000) scale, Kim (2005) identified a developmentally appropriate practice subscale which was the source of the 13 items used in the present study to measure DAP beliefs (e.g., How important is it for teachers to provide activities that are responsive to individual children's interests; How important is it for teachers to provide opportunities for children to select many of their own activities; How important is it for teachers to allocate extended periods of time for children to engage with play and projects). Teachers rated the 13 items on a 5-point scale ranging from 1 (not at all important) to 5 (extremely important). Theta for the 13 items was .96. A total scale score was used as the measure of teacher beliefs about developmentally appropriate practices.

\subsubsection{Receptiveness to PALS Training}

Two items were used to assess teachers' and teacher assistants' receptiveness to the PALS training. After each on-site training visit, the PALS coach rated the extent to which each staff was receptive to both the training process (How receptive was the teacher to participating in the training opportunities you provided?) and the training content (How receptive was the teacher to the practices that were the focus of the training?). The items were rated on a 5-point scale ranging from 1 (highly resistant) to 5 (highly receptive). A summated score averaged across the four months of training was used as the measure of receptiveness to the PALS training.

\subsubsection{Social Validity}

Teachers' and teacher assistants' judgments of the social validity (Foster \& Mash, 1999) of the early childhood classroom practices constituting the focus of training were assessed using a 12 -item scale used in previous studies where variations in social validity ratings were correlated with variations in the use of practices constituting the focus of investigation (e.g., Dunst et al., 2007; Trivette, Dunst, Masiello, Gorman, \& Hamby, 2009). Six items measured teachers' views of the social importance of the practices (e.g., These practices accomplished what I expected; These practices likely will improve important aspects of my work with children), and six items measured the acceptability of the practices (The practices were easy to incorporate into my daily schedule; The practices made sense and were logical to me). The items were rated on a 5-point scale ranging from 1 (not at all true) to 5 (very much true). Theta for the 12 items was .97. The sum of ratings on the 12 items was used as the measure of social validity of the classroom practices.

\subsection{Outcome Measures}

The outcome measures of staff participation in the professional development project included the number of training sessions attended by the staff, hours of training that the staff received, Head Start staff active engagement in the training and the use of the classroom practices during training, and Head Start staff judgments of the values and benefits of PALS.

\subsubsection{Number of Training Sessions}

The total number of training sessions attended by each teacher and teacher assistant was the dependent measure for number of training sessions. The number of sessions per classroom attended by staff ranged between 9 and 18 .

\subsubsection{Hours of Training}

The coach recorded for each training session the amount of time each teacher and teacher assistant received training. The dependent variable was the total amount of training time per participant in hours. The hours of training received by staff ranged between 24 and 50 .

\subsubsection{Staff Engagement}

The coach recorded for each training session and for each participant whether or not each teacher and teacher assistant engaged in (1) collaborative goal planning for the training, (2) used the targeted classroom practices during a training session, (3) made evaluative statements about the outcomes or benefits of the use of the practices, and (4) reflected on the use and their understanding of the practices. The number of the four staff engagement practices summed across all training sessions was the dependent measure.

\subsubsection{Head Start Staff Judgments of PALS}

Teachers and teacher assistants completed an investigator-developed scale assessing the extent to which staff participated in and experienced the different elements of PALS training and benefited from the training. The scale included 20 items, each rated on a 5-point scale ranging from 1 (not at all used) to 5 (very much used) that indicated how much the coach engaged the participants in the PALS practices (e.g., I was provided information about the important features of the practice [Introduction]; I examined my practices with my coach to determine how my practices were working [Application]; Using a performance checklist helped me see the important characteristics of the practices [Reflection]; I was able to identify the next steps in the learning process with guidance from my coach [Mastery]. A total scale score was used as the measure of staff participation in the training PALS (Theta $=.97$ ). 


\subsection{Methods of Analysis}

The relationships among the measures were first examined by correlation analyses. The focus of analysis was the nature of relationships among measures and the extent to which the patterns of covariation among the variables were consistent with the study hypotheses.

The primary analyses were supplemented by exploratory structural equation modeling (SEM; Kline, 2005) to discern which particular patterns of relationships among measures were consistent with the study hypotheses. We used the root mean square error of approximation (RMSEA), the comparative fit index (CFI), and incremental fit index (IFI) to test the fit of different models to the data to identify the best fitting model (Joreskog \& Sorborn, 2001). The closer RMSEA is to zero, and the closer CFI and IFI are to one, the better the fit of the model to the data. The standardized structural coefficients were used as the sizes of effects for the relationships among variables in the SEMs. Effect sizes with $p$-values equal to or less than 0.10 were used for substantive interpretation because of the exploratory nature of the analyses (Hoyle, 1995).

\section{Results}

\subsection{Correlation Findings}

The results are shown in Table 4. Staff judgments of the value and benefits of PALS were related to how much time staff participated in the training. Staff who attended more training sessions, as would be expected, received more hours of training. Staff who received more hours of training were more likely to be actively engaged in the training to promote the use of the classroom practices constituting the focus of training. The pattern of findings indicate that staff beliefs about the value and benefits of the training contributed to or influenced their "buy in" and participation in the training which in turn was related to their active engagement in learning to use the practices constituting the focus of training.

Table 4. Correlations Among the Predictor Variables and Head Start Staff Participation in the Professional Development Project

\begin{tabular}{|c|c|c|c|c|c|c|c|c|c|c|c|c|c|c|}
\hline \multirow[b]{2}{*}{ Study Measures } & \multicolumn{4}{|c|}{ Background Measures } & \multicolumn{4}{|c|}{ Belief Measures } & \multicolumn{2}{|c|}{$\begin{array}{c}\text { Training-Related } \\
\text { Measures }\end{array}$} & \multicolumn{4}{|c|}{ Outcome Measures } \\
\hline & $\mathrm{TA}$ & $\mathrm{ED}$ & YR & SP & WC & $\mathrm{CA}$ & PM & DAP & $\mathrm{RE}$ & SV & NS & TT & SE & PALS \\
\hline Teacher Age (TA) & - & .03 & $.48^{\text {tot }}$ & .07 & .25 & $.37^{*}$ & .21 & .19 & .16 & .27 & $.42^{\text {*t }}$ & $.30^{\circ}$ & $.42^{\circ}$ & $.48^{\text {t* }}$ \\
\hline Education (ED) & & - & -.08 & $.45^{\text {t* }}$ & -.22 & -.11 & .25 & -.05 & .02 & $-.38^{*}$ & -.12 & -.24 & -.03 & -.19 \\
\hline Years of Experience (YR) & & & - & $.33^{*}$ & .09 & $.30^{*}$ & .05 & -.04 & .12 & .04 & .14 & .16 & .19 & 23 \\
\hline Staff Position (SP) & & & & - & .13 & $30^{*}$ & .25 & .04 & .12 & -.18 & -.06 & -.04 & -.06 & .00 \\
\hline Work Climate (WC) & & & & & - & $.65^{\text {th }}$ & $.30^{*}$ & $.49 *$ & .20 & $.53^{\text {tot }}$ & .18 & .20 & .15 & 24 \\
\hline Career Aspirations (CA) & & & & & & - & $.50^{\circ *}$ & $.39^{* *}$ & .23 & $.37^{*}$ & .09 & .10 & .12 & $.48^{* *}$ \\
\hline Personal Motivation (PM) & & & & & & & - & $.63^{\text {that }}$ & .10 & .14 & .07 & -.05 & -.01 & 20 \\
\hline DAP Beliefs (DAP) & & & & & & & & - & .08 & $.40^{\circ *}$ & .10 & -.04 & .21 & .12 \\
\hline Receptiveness (RE) & & & & & & & & & - & $.43^{\text {t* }}$ & .10 & .27 & .02 & $.33^{\circ}$ \\
\hline Social Validity (SV) & & & & & & & & & & - & .08 & .25 & .08 & $.29^{*}$ \\
\hline \multicolumn{15}{|l|}{ Outcome Measures } \\
\hline Number of Sessions (NS) & & & & & & & & & & & - & $.74^{\text {thet }}$ & $.76^{\text {thth }}$ & .15 \\
\hline Training Time (TT) & & & & & & & & & & & & - & $54^{\text {that }}$ & $.34^{\circ}$ \\
\hline Staff Engagement (SE) & & & & & & & & & & & & & - & .08 \\
\hline PALS & & & & & & & & & & & & & & - \\
\hline
\end{tabular}

$* p<.05 . \quad * * p<.01 . * * * p<.001$.

None of the background variables except staff age were related to the four training outcome measures. In contrast, four of the other predictor variables were related to the staffs' judgments of the value and benefits of the training. The results showed that older staff with more professional career aspirations who were more receptive to the classroom-based training and who judged the classroom practices constituting the focus of the training as socially valid, were more likely to indicate that they participated in and benefited from the training. The fact that teacher age was the only background variable related to all four outcome measures deserves comment in light of the fact that teacher age was also related to 
years of experience and career aspirations. Staff with more years of experience were more likely to have professionally-oriented career aspirations which in turn were related to their judgments of the PALS training.

Examination of the relationships among the background variables shows that teachers compared to teacher assistants were, not unexpectedly, more likely to have more years of both formal education and experience. Teachers compared to teacher assistants were also more likely to have more professionally-oriented career aspirations. Whether or not staff were teachers or teacher assistants, however, did not matter in terms of the relationships with any of the other predictor variables or any of the four outcome measures.

Work climate proved to be the best predictor of staff belief appraisals and their judgments of the social validity of the classroom practices constituting the focus of training. Staff appraisals of the social validity of the classroom practices in turn were related to staff receptiveness to the training. The pattern of results suggest that a positive work environment contributed to positive personal belief appraisals, and staff with more positive personal belief appraisals were more likely to see the value and benefits of the training and the classroom practices constituting the focus of training. Staff social validity judgments in turn were related to staff receptiveness to the training.

\subsection{Structural Equation Model Findings}

The hypothesized relationships described earlier in the paper and the patterns of results displayed in Table 4 were used to build and test a number of structural equation models to evaluate the fit of the different models to the data. The "best fitting" model is shown in Figure 2. RMSEA was 0.00, CFI was 0.99, and IFI was 0.99, indicating an excellent fit of the model to the data.

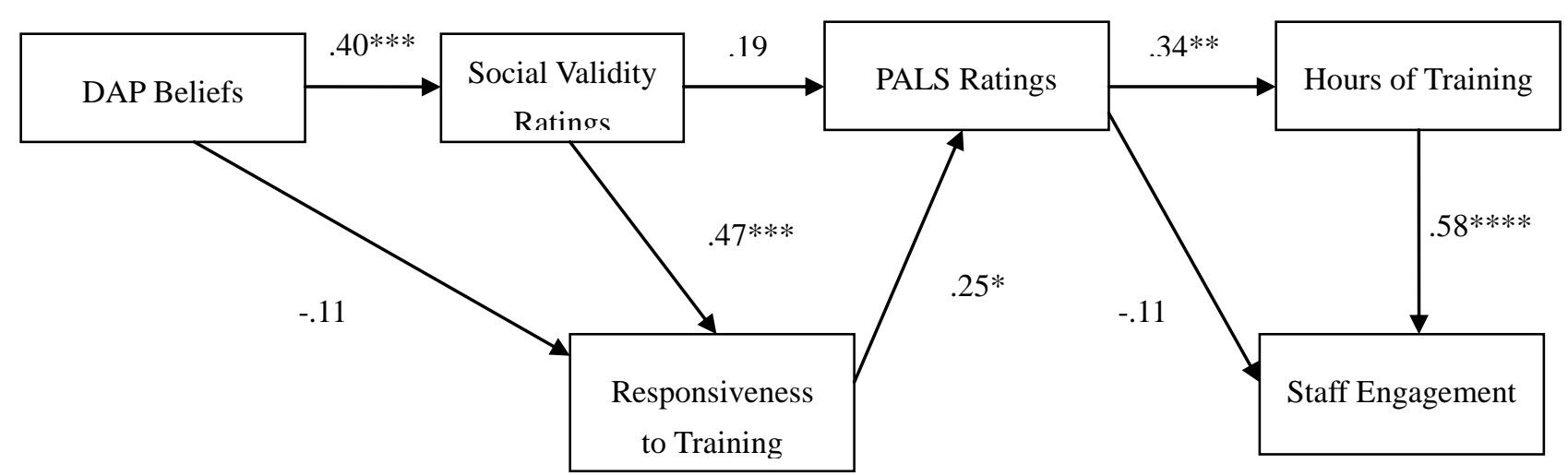

Figure 2. Exploratory structural equation modeling results for the relationships (standardized structural coefficients) between the predictor and outcome variables in the SEM. ${ }^{*} p<.08 * * p<.02 * * * p<.01 * * * * p .0001$

Results showed that the more staff believed in the importance of developmentally appropriate practices, the more socially valid they judged the classroom practices that were the focus of training. The more socially valid they judged the classroom practices, the more receptive were the staff to the training they were afforded. The more receptive the staff were to the training, the more they indicated they participated in and benefited from the PALS training. In addition to these direct effects, DAP beliefs were indirectly related to staff receptiveness to the training mediated by social validity judgments $(B=.19, p=.0296)$, and social validity judgments were indirectly related to PALS training mediated by staff receptiveness to the training $(B=.12, p=.1000)$.

The relationships between the three training measures were also as expected. The more staff reported active participation in and benefits from the PALS training, the more time (hours of training) they participated in the classroom-based training. The more hours of training staff received, the more they were actively engaged in the training to promote the use of the classroom practices constituting the focus of training. In addition, PALS training was indirectly related to active staff engagement in the use of the classroom practices mediated by hours of training $(B=.19$, $p=.0337)$.

\section{Discussion}

The nature of the relationships among the four outcome measures help elucidate the manner in which "buy in" to training is related to engagement in training. Staff judgments of the perceived value and benefits of PALS were related to how much time staff participated in the training, where time involved in training in turn was associated with active staff engagement in using the classroom practices constituting the focus of training. This was confirmed by the SEM where the relationship between PALS training and active use of the classroom training was mediated by the quantity of 
training.

\subsection{Patterns of Results}

Findings showed several noteworthy patterns of results for the relationships between the predictor and outcome measures. First, both training-related measures (receptiveness, social validity) and one personal belief measure (career aspirations) were significantly related to staff judgments of the value and benefits of the PALS training. This suggests that a number of positive practitioner belief appraisals contribute to or influence Head Start staff judgments of the training they were provided. Second, work climate was significantly related to all three belief measures as well as to staff members' judgments of the social validity of the practices constituting the focus of training. This indicates that a positive social ecology of the staff members' work environment contributed to their personal belief appraisals as well as to their beliefs about the importance and acceptability of the classroom practices. Third, staff belief appraisals (career aspirations, DAP beliefs) were related to their judgment of the social validity of the classroom practices, indicating that more positive personal belief appraisals contributed to or influenced their beliefs about the importance and acceptability of the classroom practices. Fourth, and with only a few exceptions, the staff background measures did not prove to be particularly important covariates of any of the other predictor variables. Taken together, the results suggest that there are rather complex relationships among the measures constituting the focus of analyses in our study, as has been found in other investigators (Bozack, 2008; Downer et al., 2009; Sugawara et al., 1998), but that particular personal belief appraisals stand out as the more important predictors of participation in and the perceived benefits of professional development (e.g., Livneh \& Livneh, 1999; Wagner \& French, 2010) as was found in the SEM.

The results in terms of the importance of personal beliefs as a predictor of staff participation in professional development are very much like those reported by others (e.g., Livneh \& Livneh, 1999; Wagner \& French, 2010). However, we did not find, as Livneh and Livneh (1999) did, that the level of staff education was a predictor of their participation in professional development. Rather, older staff with more years of experience were more likely to be involved in the classroom-based training.

Staff receptiveness to the PALS training was related to participants' judgments of the value and benefits of the training, where participants' judgments of the PALS training in turn were indirectly related to active engagement in learning to use the classroom practices mediated by hours of training deserves special comment by the fact that the patterns of relationships are much the same as found in other professional development studies (e.g., Foster, Oh, Azano, \& Callahan, 2012; Locasale-Crouch et al., 2012).

The fact that staff receptiveness to the training covaried with teachers' judgments of PALS was not unexpected. As part of classroom-based training we have conducted (Trivette et al., 2012a), as well as training on other kinds of early childhood practices (Dunst, Trivette, \& Deal, 2011; Swanson, Roper, Raab, \& Dunst, 2006), we have consistently found that participants differ in their receptiveness and responsiveness to training opportunities. This is consistent with Bozack's (2008) conclusion that early childhood practitioners' responsiveness to professional development opportunities is often quite varied. Variations in responsiveness, however, are not limited to training opportunities. Trivette and Raab (2011) for example, found that variations in staffs' receptiveness to the classroom practices constituting the focus of training described in this paper was the best predictor of adoption and use of the practices. The findings, taken together, suggest that variations in readiness to change may be a factor contributing to variations in receptiveness to training (Choi \& Ruona, 2013; Peterson, 2012; Peterson \& Baker, 2011).

The importance of social validity judgments as correlates of participation in the professional development afforded the staff deserves comment because it is often not acknowledged that beliefs about the value and usefulness of a practice influence the likelihood that staff will demonstrate commitment to training opportunities to promote use of a new or innovative practice. Both research and experience indicates that staff who see the value and importance of an intervention practice are more likely to seek out and participate in training to learn to use the practice, where the fidelity of the training received is likely to influence the fidelity of staff use of the intervention practice (Dunst, 2012; Dunst, Trivette, \& Raab, 2013).

\subsection{Implications for Practice}

Findings from the study have a number of implications for practice, and especially with regard to the conditions that are likely to contribute to early childhood practitioners' meaningful participation in professional development opportunities. First, professional development specialists should recognize and take into consideration the fact that a host of different practitioner beliefs are likely to influence "buy in" to training and staff willingness to participate in training afforded them. It would therefore seem worth the time and effort to informally query participants to determine the reasons they are attending a training and what they hope to learn from participation in the training to ascertain their motivation to benefit from the professional development opportunity (see e.g., Schieb \& Karabenick, 2011). 
Second, an important finding from this study, as well as other studies we have conducted (e.g., Dunst et al., 2007; Trivette et al., 2007), is that practitioners' social validity appraisals of the practices constituting the focus of training influence the likelihood that they see the value of the practices. It would therefore seem indicated as part of any training activities that professional development specialists take the time to fully describe, illustrate, and demonstrate both the key characteristics of a practice and the benefits of using the practice to heighten practitioners' beliefs about the importance and value of a practice.

Third, the training afforded practitioners to promote their use of intervention practices, to the maximum extent possible, should actively involve the practitioners in all phases of the training. This is a major feature of PALS (see especially Dunst \& Raab, 2010; Dunst, Trivette et al., 2011; Trivette et al., 2012a, 2012b), and is one reason this approach to professional development has proven highly effective (see also National Center on Child Care Professional Development Systems and Workforce Initiatives, 2013; Neuman \& Kamil, 2010).

\subsection{Research Needs and Challenges}

The complex relationships found in this study indicated that staff with more positive belief appraisals are more willing to fully participate in professional development opportunities to promote their use of evidence-based classroom practices. Disentangling the relationships among career aspirations, personal motivation, DAP beliefs, and beliefs about the social validity of the practices constituting the focus of the training will require additional research to understand which of these factors have the strongest influence on the outcomes of professional development training. Models and frameworks formulated by Sheridan et al. (2009) and Weiss et al. (2013) should prove useful for conceptualizing and conducting this type of research.

Including multiple measures of teachers' personal belief appraisals (as well as other constructs) as part of professional development research also would permit researchers to address questions of What works and for whom? (Welch-Ross, Wolf, Moorhouse, \& Rathgeb, 2006) where the results can be used to identify the most important characteristics of recommend evidence-based professional development practices that can facilitate early childhood practitioners pursuing training and professional development. The findings described in this paper indicate a need for additional empirical studies conducted with larger and more diverse samples of Head Start staff to be able to examine both the main, interactional, and mediational effects of the personal beliefs and social validity appraisals on active staff receptiveness and participation in training. As noted by Sheridan et al. (2009), it is still the case that there is a critical need to identify the processes and interactions of personal, contextual, and systemic variables that impact the adoption and use of evidence-based early childhood classroom practices. However, the challenge of this type of research is that it must be on a larger scale and be ecologically valid in order to yield results that inform practice at a variety of programmatic levels (e.g., Welch-Ross et al., 2006).

\section{Conclusion}

Findings described in this paper indicate a need to consider a range of variables that contribute to Head Start staff participation in professional development activities to promote the adoption and use of evidence-based classroom practice. Explicit recognition and consideration of professional development as an implementation practice, classroom practice as an intervention practice (Dunst, 2012; Dunst et al., 2014) and the factors that influence beliefs and behaviors related to both types of practices, should lead to a better understanding of the relationship between beliefs, participation in training, and use of evidence-based classroom practices (Sheridan et al., 2009; Trivette \& Raab, 2011).

\section{Acknowledgements}

The research reported in this paper was supported, in part, by funding from the U.S. Department of Health and Human Services, Administration for Children and Families, Office of Planning, Research and Evaluation (Grant \# 90YR0021). The opinions expressed, however, are those of the authors and do not necessarily represent the official opinions or position of the Department or Office. Appreciation is extended to Deborah W. Hamby for the data analysis described in the paper.

\section{References}

Bozack, A. R. (2008). Growing new teachers: The relationship among professional development, efficacy beliefs, and classroom practices. Dissertation Abstracts International Section A: Humanities and Social Sciences, 69(2-A).

Bredekamp, S., \& Copple, C. (Eds.). (1997). Developmentally appropriate practice in early childhood programs (Rev. ed.). Washington, DC: National Association for the Education of Young Children.

Bruder, M. B., Dunst, C. J., Wilson, C., \& Stayton, V. (2013). Predictors of confidence and competence among early childhood interventionists. Journal of Early Childhood Teacher Education, 34(3), 249-267. http://dx.doi.org/10.1080/10901027.2013.816806. 
Burts, D. C., Buchanan, T. K., Charlesworth, R., \& Jambunathan, S. (2000). Rating scale for measuring the degree of developmentally appropriate practice in early childhood classrooms (3-5 year olds). Baton Rouge, LA: Louisiana State University College of Education.

Carmines, E. G., \& Zeller, R. A. (1979). Reliability and validity assessment (Quantitative Applications in the Social Sciences No. 17). Newbury Park, CA: Sage. http://dx.doi.org/10.4135/9781412985642.

Charlesworth, R., Hart, C. H., Burts, D. C., \& Hernandez, S. (1991). Kindergarten teachers beliefs and practices. Early Child Development and Care, 70, 17-35. http://dx.doi.org/10.1080/0300443910700103.

Choi, M., \& Ruona, W. E. (2013). Individual readiness for organizational change. In H. S. Leonard \& J. Passmore (Eds.), The Wiley-Blackwell Handbook of the Psychology of Leadership, Change, and Organizational Development (pp. 331-345). New York: John Wiley. http://dx.doi.org/10.1002/9781118326404.ch16.

Domitrovich, C. E., Gest, S. D., Sukhdeep, G., Jones, D., \& DeRousie, R. S. (2009). Individual factors associated with professional development training outcomes of the Head Start REDI program. Early Education and Development, 20, 402-430. http://dx.doi.org/10.1080/10409280802680854.

Downer, J. T., Locasale-Crouch, J., Hamre, B., \& Pianta, R. (2009). Teacher characteristics associated with responsiveness and exposure to consultation and online professional development resources. Early Education and Development, 20, 431-455. http://dx.doi.org/10.1080/10409280802688626.

Dunst, C. J. (2012, February). Framework for conceptualizing the relationship between evidence-based implementation and intervention practices. Presentation made at the Conference on Research Innovations in Early Intervention, San Diego, CA. Available at http://utilization.info/presentations.php.

Dunst, C. J., Bruder, M. B., Trivette, C. M., Raab, M., \& McLean, M. (2001). Natural learning opportunities for infants, toddlers, and preschoolers. Young Exceptional Children, 4(3), 18-25. http://dx.doi.org/10.1177/109625060100400303.

Dunst, C. J., Pace, J., \& Hamby, D. W. (2007). Evaluation of the Games for Growing tool kit for promoting early contingency learning (Winterberry Research Perspectives Vol. 1, No. 6). Asheville, NC: Winterberry Press.

Dunst, C. J., \& Raab, M. (2010). Practitioners' self-evaluations of contrasting types of professional development. Journal of Early Intervention, 32, 239-254. http://dx.doi.org/10.1177/1053815110384702.

Dunst, C. J., \& Raab, M. (2012). Interest-based child participation in everyday learning activities. In N. M. Seel (Ed.), Encyclopedia of the sciences of learning. New York: Springer. http://dx.doi.org/10.1007/978-1-4419-1428-6.

Dunst, C. J., Raab, M., \& Trivette, C. M. (2011). Characteristics of naturalistic language intervention strategies. Journal of Speech-Language Pathology and Applied Behavior Analysis, 5(3-4), 8-16. Retrieved from http://www.baojournal.com/SLP-ABA\%20WEBSITE/index.html.

Dunst, C. J., \& Trivette, C. M. (2009). Let's be PALS: An evidence-based approach to professional development. Infants and Young Children, 22(3), 164-175. http://dx.doi.org/10.1097/IYC.0b013e3181abe169.

Dunst, C. J., Trivette, C. M., \& Deal, A. G. (2011). Effects of in-service training on early intervention practitioners' use of family systems intervention practices in the USA. Professional Development in Education, 37, 181-196. http://dx.doi.org/10.1080/19415257.2010.527779.

Dunst, C. J., Trivette, C. M., \& Raab, M. (2013). An implementation science framework for conceptualizing and operationalizing fidelity in early childhood intervention studies. Journal of Early Intervention. Online version at http://jei.sagepub.com/content/early/2013/09/03/1053815113502235.

http://dx.doi.org/10.1177/1053815113502235.

Dunst, C. J., Trivette, C. M., \& Raab, M. (2014). Utility of implementation and intervention performance checklists for conducting research in early childhood education. In O. Saracho (Ed.), Handbook of research methods in early childhood education: Vol.1. Research methodologies (pp. 247-276). Charlotte, NC: Information Age Publishing.

Dunst, C. J., Watson, A., Roper, N., \& Batman, D. (2011). Factors associated with employee appraisals of adherence to learning organization principles and practices. E-Journal of Organizational Learning and Leadership, 9(2), 81-93. Retrieved from http://www.leadingtoday.org/weleadinlearning/Winter2011/Article\%205\%20-\%20Jones.pdf.

Ellis, P. J. (1998). The relationship of teacher education, training, and beliefs to program quality in Head Start. Dissertation Abstracts International: Section A: Humanities and Social Sciences, 59(2), 413.

Foster, L., Oh, S., Azano, A., \& Callahan, C. (2012, March). Adherence: A more nuanced usage of fidelity of implementation's core component to capture variation in treatment effects. Paper presented at the Spring 
Conference of the Society for Research on Educational Effectiveness, Washington, DC.

Foster, S. L., \& Mash, E. J. (1999). Assessing social validity in clinical treatment research issues and procedures. Journal of Consulting and Clinical Psychology, 67, 308-319. http://dx.doi.org/10.1037/0022-006X.67.3.308.

Hoyle, R. (1995). The structural equation modeling approach: Basic concepts and fundamental issues. In R. Hoyle (Ed.), Structural equation modeling: Concepts, issues, and applications (pp. 1-36). Thousand Oaks, CA: Sage.

Joreskog, K. G., \& Sorborn, D. (2001). LISREL 8.5 for Windows [Computer software]. Skokie, IL: Scientific Software International.

Kim, K.-R. (2005). Teacher beliefs and practices survey: Operationalizing the 1997 NAEYC guidelines (Doctoral dissertation). Retrieved from http://etd.lsu.edu/docs/available/etd-07072005-001118/unrestricted/Kim_dis.pdf.

Kline, R. B. (2005). Principles and practice of structural equation modeling (2nd ed.). New York: Guilford Press.

Livneh, C., \& Livneh, H. (1999). Continuing professional education among educators: Predictors of participation in learning activities. Adult Education Quarterly, 49, 91-106. http://dx.doi.org/10.1177/074171369904900202.

Locasale-Crouch, J., DeCoster, J., Cabell, S., Hamre, B., Downer, J., \& Pianta, R. (2012, March). Variation in teachers' instructional interactions within two interventions: Associations with intervention quality and responsiveness. Presentation made at the Spring Conference of the Society for Research on Educational Effectiveness, Washington, DC.

National Center on Child Care Professional Development Systems and Workforce Initiatives (PDW Center). (2013). Aligned professional development systems planning and implementation guide. Washington, D. C.: ACF's Office of Child Care and Office of Head http://childcare.gov/sites/default/files/20130823_rev_pdwcenter_alignedpds_considerations_508prepfinal.pdf.

Neuman, S. B., \& Kamil, M. L. (2010). Preparing teachers for the early childhood classroom: Proven models and key principles. Baltimore: Brookes.

Neuman, S. B., \& Wright, T. S. (2010). Promoting language and literacy development for early childhood educators: A mixed-methods study of coursework and coaching. The Elementary School Journal, 111(1), 63-86. http://dx.doi.org/10.1086/653470.

Peterson, S. M. (2012). Understanding early educators' readiness to change. NHSA Dialog, 15(1), 95-112. http://dx.doi.org/10.1080/15240754.2011.636492.

Peterson, S. M., \& Baker, A. C. (2011). Readiness to change in communities, organizations, and individuals. In J. A. Sutterby (Ed.), The Early Childhood Educator Professional Development Grant: Reasearch and Practice (Advances in Early Education and Day Care, Volume 15) (pp. 33-59). Emerald Group Publishing Limited. http://dx.doi.org/10.1108/S0270-4021(2011)0000015006.

Raab, M., \& Dunst, C. J. (2007). Influence of child interests on variations in child behavior and functioning (Winterberry Research Syntheses Vol. 1, No. 21). Asheville, NC: Winterberry Press.

Raab, M., \& Dunst, C. J. (2009). Magic seven steps to responsive teaching: Revised and updated (Winterberry Practice Guides). Asheville, NC: Winterberry Press.

Ramey, S. L., Crowell, N. A., Ramey, C. T., Grace, C., Timraz, N., \& Davis, L. E. (2011). The dosage of professional development for early childhood professionals: How the amount and density of professional development may influence its effectiveness. In J. A. Sutterby (Ed.), The early childhood educator professional development grant: Research and practice (Advances in early education and day care, Volume 15) (pp. 11-32). Emerald Group Publishing Limited. http://dx.doi.org/10.1108/S0270-4021(2011)0000015005

Schieb, L. J., \& Karabenick, S. A. (2011). Teacher motivation and professional development: A guide to resources. Math and Science Partnership - Motivation Assessment Program. Ann Arbor, MI: University of Michigan.

Sheridan, S. M., Edwards, C. P., Marvin, C. A., \& Knoche, L. L. (2009). Professional development in early childhood programs: Process issues and research needs. Early Education and Development, 20, 377-401. http://dx.doi.org/10.1080/10409280802582795.

Snell, M. E., Forston, L. D., Stanton-Chapman, T. L., \& Walker, V. L. (2012). A review of 20 years of research on professional development interventions for preschool teachers and staff. Early Child Development and Care, O(0), 1-17. http://dx.doi.org/10.1080/03004430.2012.702112.

Sugawara, A. I., Ruder, T. P., \& Burt, L. M. (1998). Relationships between teaching self-efficacy, work environment autonomy, and teacher competency among early childhood preservice teachers. Journal of Early Childhood 
Teacher Education, 19, 3-8. http://dx.doi.org/10.1080/0163638980190102.

Swanson, J., Roper, N., Raab, M., \& Dunst, C. J. (2006). Practitioner judgments of the usefulness of contextually mediated practices training activities. CASEinPoint, 2(9), 1-7. Available at http://www.fippcase.org/caseinpoint/caseinpoint_vol2_no9.pdf.

Torquati, J. C., Raikes, H., \& Huddleston-Casas, C. A. (2007). Teacher education, motivation, compensation, workplace support, and links to quality of center-based child care and teachers' intention to stay in the early childhood profession. Early Childhood Research Quarterly, 22, 261-275. http://dx.doi.org/10.1016/j.ecresq.2007.03.004.

Tout, K., Zaslow, M., \& Berry, D. (2006). Quality and qualifications: Links between professional development and quality in early care and education settings. In M. Zaslow \& I. Martinez-Beck (Eds.), Critical issues in early childhood professional development (pp. 77-110). Baltimore: Brookes.

Trivette, C. M., Dunst, C. J., Hamby, D. W., \& Pace, J. (2007). Evaluation of the Tune In and Respond tool kit for promoting child cognitive and social-emotional development (Winterberry Research Perspectives Vol. 1, No. 7). Asheville, NC: Winterberry Press.

Trivette, C. M., Dunst, C. J., Masiello, T., Gorman, E., \& Hamby, D. W. (2009). Social validity of the Center for Early Literacy Learning parent practice guides. CELLpapers, 4(1), 1-4. Available at http://www.earlyliteracylearning.org/cellpapers/cellpapers_v4n1.pdf.

Trivette, C. M., \& Raab, M. (2011, April). Relationship between teacher characteristics, professional development procedures, and teachers' adoption of classroom practices. In W. DeCourcey \& L. Hoard (Chairs), Coaching/mentoring: For whom and under what conditions. Symposium conducted at the biennial meeting of the Society for Research in Child Development, Montreal, Canada.

Trivette, C. M., Raab, M., \& Dunst, C. J. (2012a). An evidence-based approach to professional development in Head Start classrooms. NHSA Dialog, 15, 41-58. http://dx.doi.org/10.1080/15240754.2011.636489.

Trivette, C. M., Raab, M., \& Dunst, C. J. (2012b). Steps to successful professional development in Head Start. NHSA Dialog, 15, 127-134. http://dx.doi.org/10.1080/15240754.2011.637644.

Vartuli, S. (1999). How early childhood teacher beliefs vary across grade level. Early Childhood Research Quarterly, 14, 489-514. http://dx.doi.org/10.1016/S0885-2006(99)00026-5.

Wagner, B. D., \& French, L. (2010). Motivation, work satisfaction, and teacher change among early childhood teachers. Journal of Research in Childhood Education, 24, 152-171. http://dx.doi.org/10.1080/02568541003635268.

Weiss, M. J., Bloom, H. S., \& Brock, T. (2013). A conceptual framework for studying the sources of variation in program effects. In MDRC Working Papers on Research Methodology. New York: mdrc. http://mdrc.clevernamehere.com/sites/default/files/a-conceptual_framework_for_studying_the_sources.pdf.

Welch-Ross, M., Wolf, A., Moorhouse, M., \& Rathgeb, C. (2006). Improving connections between professional development research and early childhood policies. In M. Zaslow \& I. Martinez-Beck (Eds.), Critical issues in early childhood professional development (pp. 369-394). Baltimore: Brookes.

\section{$($ (c) $)$ EY}

This work is licensed under a Creative Commons Attribution 3.0 License. 